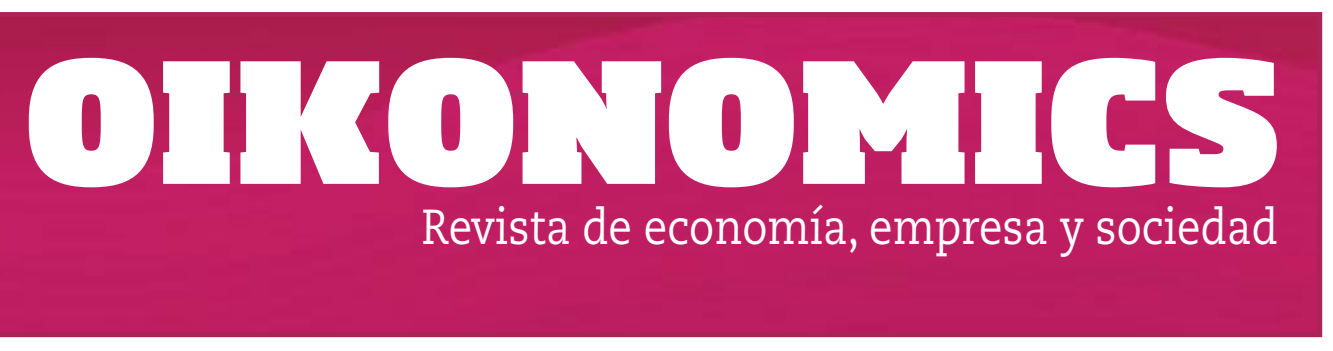

NUEVOS DESAFÍOS

\title{
Dirigir personas para transformar las organizaciones en tiempos de incertidumbre
}

\section{Pilar Ficapal-Gusí}

Directora del Máster Universitario en Dirección y Gestión de Recursos Humanos (UOC)

El entorno laboral contemporáneo está experimentando cambios vertiginosos. Estas importantes transformaciones en el trabajo se han ido trasladando a las organizaciones a diferente ritmo, de forma que, hoy en día, nos encontramos en un período de transición, desde empresas que todavía mantienen características de una estructura organizativa tradicional y clásica hasta aquellas que han adoptado modelos organizativos novedosos propios de la economía global del conocimiento, que permiten adaptar mejor su actividad a entornos inciertos y complejos.

Desde el ámbito de los recursos humanos, recientemente se ha utilizado el acrónimo VUCA (Volatility, Uncertainly, Complexity, Ambiguity) para describir este contexto que requiere emprender proyectos de transformación en las organizaciones. La capacidad de respuesta y adaptación de las empresas a los cambios del entorno es determinante para ser competitivo en un contexto en que los empresarios, líderes y directivos se enfrentan a situaciones que, a diferencia otros tiempos, se alejan de la estabilidad y la previsibilidad. Así lo corrobora la literatura sobre el management que enfatiza la necesidad de establecer cambios sustanciales en la estrategia, en la forma de dirigir las organizaciones y de gestionar el talento, y de implementar nuevas prácticas de la organización del trabajo y de recursos humanos que permitan una mayor eficiencia a la hora de tomar decisiones en función del entorno. No obstante, la investigación académica también ha evidenciado que debe garantizarse el bienestar y la calidad de las condiciones de trabajo de los empleados para que haya beneficios mutuos, tanto para la organización como para los trabajadores. 
Un aspecto nuclear de las transformaciones en el mundo del trabajo se encuentra en los procesos de digitalización y tecnologización. Estos procesos aportan beneficios sustanciales en términos de competitividad y productividad cuando se asientan. No obstante, si no existe la capacidad de crear trabajo con mayor calidad y gestionar el cambio a través de la capacitación en su uso, las tecnologías también pueden comportar riesgos, tales como pérdidas de puestos de trabajo, exclusión de empleo por el sesgo de habilidades, disminución de la calidad del trabajo o aumentos de la desigualdad. Por todo ello, es necesario disponer de herramientas para evaluar la gestión de personas y el impacto de sus intervenciones a nivel individual, grupal y organizativo.

Este monográfico pretende integrar todos estos aspectos y proporcionar diferentes perspectivas de los retos a que se enfrentan los profesionales de la dirección de personas desde diferentes dimensiones: empresarial y económica, psicosocial y legislativa.

Abre el monográfico el artículo «El objetivo de dirigir empresas es crear justicia». Natàlia Cugueró y Josep Maria Rosanas consideran necesario el logro de este objetivo para que la empresa tenga sentido para todos los grupos de interés y sea sostenible. Según los autores, para tomar decisiones justas, es necesario incorporar la sabiduría práctica propuesta por Aristóteles, y entender cuáles deben ser los valores (virtudes) que alimenten las decisiones. De esta forma, la empresa puede generar su objetivo social que es la eudaimonia (felicidad).

Francisco Fermín Mallén y Emilio Domínguez, en el artículo «Del yo al nosotros: nuevas formas de liderar», nos presentan las características de los liderazgos emergentes o contemporáneos. El artículo explica cómo emerge, en el ámbito organizativo, esta nueva corriente de estilos de liderazgo, que tiene como denominador común la relevancia de los valores humanos y la preocupación por los demás.

Eva Rimbau estrecha la brecha entre el mundo académico y la práctica profesional a través de su artículo "Dirección de personas basada en evidencias. ¿Qué es, por qué importa, cómo implementarla?». Explica el proceso para la aplicación de la gestión basada en evidencias y ofrece sugerencias prácticas para su implementación. Así mismo, señala las razones por las que conviene adoptar este enfoque para la toma de decisiones y comenta también sus principales objeciones.

La adaptación del mercado de trabajo al entorno económico ha hecho aflorar la necesidad de proporcionar flexibilidad laboral a las empresas. Sin embargo, la manera de proporcionar esa flexibilidad y al mismo tiempo garantizar la seguridad de los trabajadores se ha convertido en una de las cuestiones que ha suscitado más interés y controversia en el ámbito de las relaciones laborales contemporáneas. Purificación Baldoví, en su artículo «Flexiseguridad o del paradigma del welfare al workfare en el actual contexto poscrisis español», se adentra en esta controversia 
y nos plantea diferentes propuestas para hacer converger ambos conceptos, así como la necesidad de establecer un debate entre las diferentes sensibilidades sociales y políticas.

Helena Thomas nos interpela sobre si «¿Hay empreses saludables?» y nos propone diferentes maneras de responder a esta cuestión. En su artículo se analizan los efectos de la puesta en práctica de diferentes programas y se presentan diferentes modelos válidos y testeados de empresas saludables para que los responsables de personas elijan el modelo más útli y evalúen la empresa en función de su organización y sus prácticas de gestión de personas.

El monográfico profundiza en la temática de la salud ocupacional a través de la investigación «Pasión y adicción al trabajo». Con el fin de determinar si son conceptos diferentes, María José Serrano analiza ambos constructos y determina la capacidad predictiva de diferentes variables, como la personalidad, el engagement, la autoeficacia, la obsesión, la satisfacción por la vida y el estilo de vida.

Desde una perspectiva muy vinculada al ámbito profesional, Verònica Platas, en su artículo «Digitalización de la gestión de personas», realiza un recorrido sobre la evolución y funcionalidades de determinadas herramientas digitales, cómo han transformado estas las prácticas de recursos humanos, por ejemplo el reclutamiento de personas, y cuál es el estado actual de su implantación.

Cierra el monográfico Joan Torrent con «El trabajo en la nueva ola digital: ¿robots humanos o recursos humanos?». En este artículo se analizan las implicaciones futuras (o no tan futuras) para el trabajo de la nueva robótica y centra su atención en las repercusiones que ello tiene para la dirección y gestión de recursos humanos. Analiza las posturas positivas, así como las más contrarias a los efectos de la tecnologización, y pone de relieve los miedos y la preocupación por el futuro del trabajo propios de cualquier proceso de cambio disruptivo en la tecnología. Asimismo, incide sobre las nuevas formas de trabajo contingente.

Palabras clave del monográfico como justicia, liderazgo, valores, toma de decisiones, empoderamiento, flexibilidad y seguridad, empresa saludable y riesgos psicosociales, desarrollo de personas, digitalitzación, robótica, inteligencia artificial y trabajo contingente nos acercan a los desafíos que afronta la dirección de personas para la transformación de las organizaciones. La dirección de personas tiene un largo y retador camino por delante. 


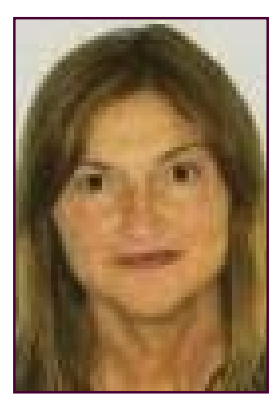

\section{Pilar Ficapal-Gusí pficapal@uoc.edu \\ Profesora de los Estudios de Economía y Empresa (UOC)}

Doctora en Sociedad de la Información y el Conocimiento (UOC). Licenciada en Psicología por la Universidad Autónoma de BarceIona y DEA en Recursos Humanos y Organizaciones por la Universidad de Barcelona. Directora del Máster universitario en Dirección y Gestión de Recursos Humanos de la UOC. Es miembro del grupo de investigación I2TIC y autora de varios libros y artículos en revistas indexadas en el ámbito de los recursos humanos, centrados en la organización, la productividad y la calidad de vida en el trabajo. Web personal: http://i2tic.net/es/equipo/pilar-ficapal/

Los textos publicados en esta revista están sujetas -salvo que se indique el contrario- a una licencia de Reconocimiento 3.0 España de Creative Commons. Podéis copiarlos, distribuirlos, comunicarlos públicamente y hacer obras derivadas siempre que reconozcáis los créditos de las obras (autoría, nombre de la revista, institución editora) de la manera especificada por los autores o por la revista. La licencia completa se puede consultar en http://creativecommons.org/licenses/by/3.0/es/deed.ca.

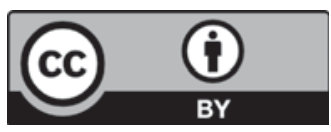

